\title{
Dependence of evoked cortical association responses on behavioral variables'
}

Jon A. Shaw and Richard F. Thompson
UNIVERSITY OF OREGON MEDICAL SCHOOL

\begin{abstract}
Evoked responses to auditory, visual and tactile stimulation were recorded from posterior association cortex in the normal waking cat. Association response amplitudes to all modalities of stimulation decreased during bodily activity and during novel stimulation of any modality. Association responses to repeated auditory stimulation did not habituate.
\end{abstract}

\section{Problem}

Although there have been many investigations of primary sensory evoked responses in the normal waking cat, little information is available concerning nonspecific evoked responses recorded from "association" areas of the cortex with this preparation. Responses of the suprasylvian gyrus to tactile nerve stimulation have been reported to decrease during EEG arousal (AlbeFessard et al., 1960). In the chloralosed cat there are four restricted cortical association response foci which respond in an equivalent fashion to all modalities of stimulation (Thompson et al., 1963). This study was planned to investigate characteristics of posterior cortical association responses in the normal waking cat and their possible dependence upon behavioral variables.

Method

A total of 50 bipolar electrodes recording across the cortex were implanted in the suprasylvian gyrus in 16 cats. Recording was such that upward deflections on the oscilloscope represented positivity at the surface electrode relative to the depth electrode. Animals were studied one week after implantation. Stimuli were an 80-db free-field click, shock to ipsilateral forepaw skin through implanted wire sutures, and light flash. Head position was monitored in all procedures.

Two independent variables were studied: "behavioral state" and habituation. Two classes of behavioral state were defined, one by a simple rating scale of bodily activity and the other in terms of novel stimulus presentation, novel meaning any stimulus of "significance", to the animal which was not otherwise present in the experiment. Samples of 20 or more consecutive evoked responses to stimuligiven once every 2 sec. were photographically superimposed for each condition of bodily activity, novel stimulus presentation and habituation testing. Habituation training was a click every $2 \mathrm{sec}$. for $70 \mathrm{hr}$. Control records for behavioral state, and all records for habituation, were taken when the animal was sitting or lying motionless with eyes open. Evoked association response amplitudes were normally distributed, permitting use of various statistical approximation methods (Dixon \& Massey, 1957, pp. 272-275).

\section{Results}

The distributions of evoked association responses along the posterior portion of the middle suprasylvian gyrus to all three modalities of stimulation are illustrated in Fig. 1. Responses are elicited by all stimuli and have approximately the same areal distribution for each, a constant finding in all animals studied. Short latency responses to visual stimulation are also seen at electrodes one and two in Fig. 1. These represent primary responses from the third visual area of the middle suprasylvian sulcus (Marshall et al., 1943) and have a more widespread distribution in the waking brain than with anesthetics. Foci of maximum association response amplitude tend to correspond in location to those seen using chloralose, although responsive areas appear more widespread without anesthesia. Association response latencies and waveforms are comparable for both conditions but amplitudes are much lower in the normal waking animal.

Effects of bodily movement on evoked association response amplitudes are given in Table $1 \mathrm{~A}$. In all cases the test response amplitudes were significantly reduced during spontaneous bodily movement. Responses returned to control levels upon cessation of activity. Table 1B illustrates the effects of novel stimuli of all three modalities on response amplitudes for each modality of

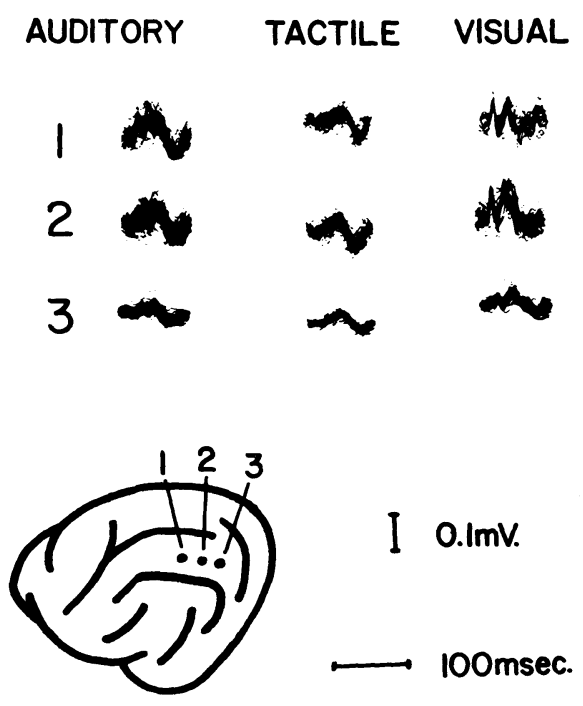

Fig. 1. Evoked cortical association responses to three modalities of stimulation. Each response represents 30 superimposed tracings. Upward deflections indicate surface positivity. 


\section{Mean amplitudes of evoked cortical association responses (in $\mu \mathrm{V}$ ) \\ for various behavioral states ( $\mathbb{N} \geq 20$ for each)}

Cortical response evoking stimulus

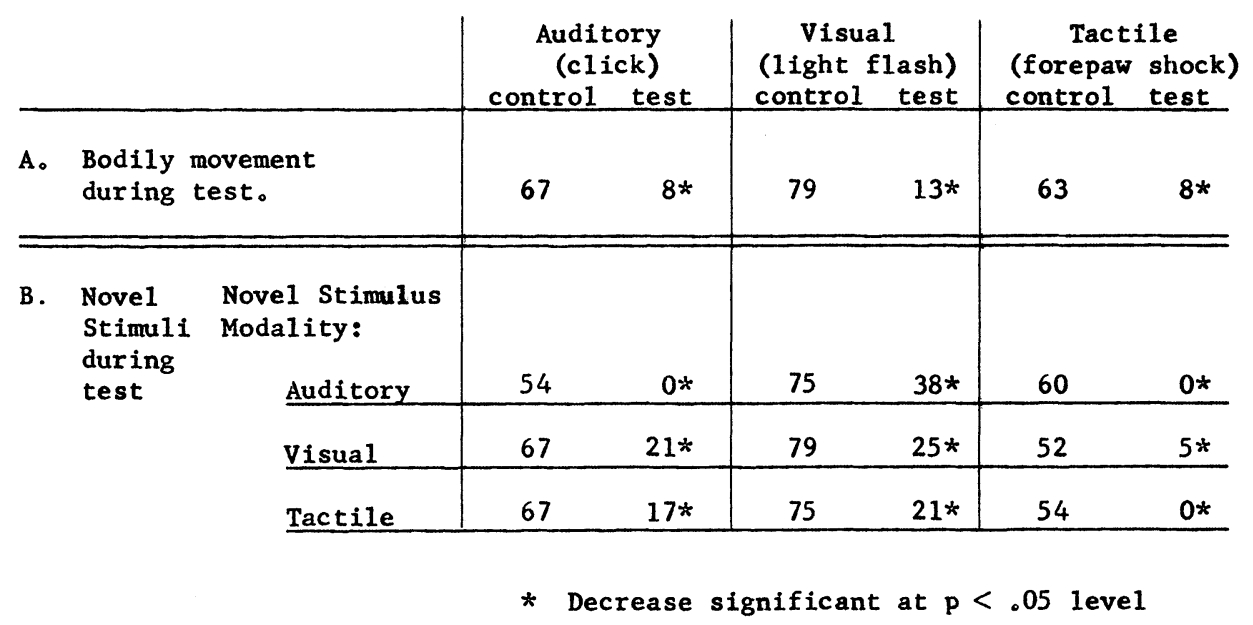

Table 1. Mean amplitudes of evoked cortical association responses (in $\mu \mathrm{V}$ ) for various behavioral states ( $\geq 20$ for each)

response evoking stimulus. In all instances amplitudes decreased significantly during novel stimulus presentation. All responses recovered to control levels within 2 min. after the novel stimulus was withdrawn. Identical results were obtained for responses evoked by clicks delivered through a microspeaker embedded in the inner portion of the external ear, ruling out variations in sound field intensity as a source of error for click stimulation. Habituation to repeated click was tested every $14 \mathrm{hr}$. or less during the $70 \mathrm{hr}$. training period. Although irregular but occasionally significant waxing and waning of responses were present in several series, no consisten and significant habituation over time was found in any series.

\section{Discussion}

Evoked responses recorded from posterior association areas of the normal waking cat are similar in most characteristics to those obtained using chloralose. Response amplitudes are extremely labile, but appear predictively related to behavioral state in that they are reduced during bodily activity and during novel stimulus presentation. The latter finding is consistent with earlier studies of primary sensory evoked responses (e. g. Hernandez-Peon et al., 1956), but the fact that responses of all modalities decrease during novel stimulation of any modality does not support the earlier hypothesis that inputs of irrelevant modalities are suppressed, at least for association responses. The absence of association response habituation to repeated click stimulation differs from earlier reports of evoked response habituation in the primary auditory system (Hernandez-Peon et al., 1957) but is consistent with the negative findings of more recent studies (Worden \& Marsh, 1963).

\section{References}

ALBE-FESSARD, D., MALlaRT, A., \& ALEONARD, P. Résponses cérébrales évoquées enregistrées chez le Chat éveille' libre et compartment attentif. J. Physiol. (Paris), 1960, 52, 7.

DIXON, W., \& MASSEY, F. Introduction to statistical analysis. New York: McGraw-Hill, 1957.

HERNANDEZ-PEON, R., JOUVET, M., \& SCHERRER, H. Auditory potentials of cochlear nucleus during acoustic habituation. Acta Neurol. Latinoamer. , 1957, 3, 144-156.

HERNANDEZ-PEON, R., SHERRER, H., \& JOUVET, M. Modification of electric activity in cochlear nucleus during "attention" in unanesthetized cats. Science, 1956, 123, 331-332.

MARSHALL, W. H., TALBOT, S. A., \& ADES, H. W. Cortical response of the anesthetized cat to gross photic and electrical afferent stimulation. J. Neurophysiol., 1943, 6, 1-15.

THOMPSON, R. F., JOHNSON, R. H., \& HOOPES, J. J. Organization of auditory, somatic sensory, and visual projection to association fields of cerebral cortex in the cat. J. Neurophysiol., 1963, 26, 343-364.

WORDEN, F. G., \& MARSH, J. T. Amplitude changes of auditory potentials evoked at cochlear nucleus during acoustic habituation. EEG and clin. Neurophysiol., 1963, 15, 866-881.

Note

1. Supported in part by grant B-2161 from the National Institutes of Health (NINDB). 